[Agr. Biol. Chem., Vol. 35, No. 10, p. 1526 1534, 1971]

\title{
Fluorescent Glycosides Accumulated in Taphrina wiesneri-infected Cherry Stems
}

\author{
Part I. ${ }^{\dagger}$ Contents of Glycosides, and the Isolation and \\ Identification of Gentisic Acid-5- $\beta$-D-glucoside
}

\author{
By Satoshi Fujil, Hiroo AokI, ${ }^{*}$ Masahiko Komoto \\ and Katsura Munakata* \\ Faculty of Agriculture, Kobe University, Kobe; \\ * Faculty of Agriculture, Nagoya University, Nagoya \\ Received March 13, 1971
}

\begin{abstract}
It was observed that three kinds of fluorescent glycosides (FG-1, FG-2, and FG-3) were more abundantly accumulated in Taphrina wiesneri-infected cherry (Prunus yedoensis) stems than in healthy ones. The contents of FG-1, FG-2, and FG-3 in infected stems were, respectively, 2.7, 7.2, and 4.3 times those in healthy stems. In dryed infected stems, FG-1, FG-2, and FG-3, amounted respectively to $0.005,0.18$, and $0.12 \%$ in the bark part; and to $0.003,0.048$, and $0.008,8$ in the wood part.

FG-1 was isolated in crystalline form, and was identified with gentisic acid-5- $\beta$-D-glucopyranoside by the comparison of its chemical and physical properties with those of synthe-

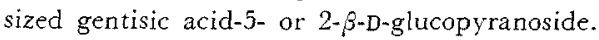

When the Japanese flowering cherry is infected by Taphrina teiesneri various symptoms appear. In previous papers, ${ }^{1,21}$ we dealt with the chemical components of infected cherry leaves and found that the melilotic acid content in infected leaves was higher than that in healthy ones. Next we examined the chemical components of infected stems.

In a preliminary experiment, paperchromatographic comparisons between components of infected cherry stems and those of healthy ones were carried out according to method described in a previous paper. ${ }^{11}$ Chromatograms of components extracted by organic

$\dagger$ This paper constitutes Part IV of "Studies on the Hypertrophic Disease of Cherry (Genus Prunus) So-called "Witch's Broom" Caused by Taphrina wiesneri."

1) S. Fujii, H. Aoki, M. Kômoto and Kr. Munakata, Agr. Biol. Chem., 32, 816 (1968).

2) idem, ibid., 35, 1133 (1971). solvents (petroleum ether, diethyl ether, chloroform or ethanol) showed no remarkable differences between infected stems and healthy ones. However, in water extracts, some fluorescent compounds were found which were more abundantly accumulated in infected stems. In ether extracts, coumarin, $o$ - and $p$ coumaric acid, vanillic acid, and $p$-hydroxybenzoic acid as well as gentisic acid were contained as common components of infected and healthy stems. In addition, the substance named F- 1 in a previous paper, ${ }^{11}$ a component of leaves, could be identified with gentisic acid using paper chromatography.

Fluorescent compounds were of three types, named FG-1, FG-2, and FG-3, $(R f=0.42,0.39$ and 0.35 on paper chromatograms. Solvent system: $n$-BuOH-AcOH- $\mathrm{H}_{2} \mathrm{O}=6: 1: 1$ ), respectively. Since these compounds were hydrolyzed by hydrochloric acid to give reducing sugars and a phenolic aglycon (paper chromato- 
graphy), it was suggested that they were similar glycosides.

This paper is concerned with the estimation of their relative amounts and with the identification of FG-1.

\section{EXPERIMENTAL AND RESULTS}

Mps are uncorrected. IR spectra were measured with a Hitachi EPI-S2 infrared spectrophotometer. UV spectra were recorded with a Hitachi EPS-2 recording spectrophotometer. NMR spectra were recorded at 100 $\mathrm{MHz}$ with a Japan Electron Optics Lab. JNM-4H-100 spectrometer. Optical rotations were measured with a Yanagimoto OR-10 photomagnetic direct reading polarimeter.

\section{Estimation of fluorescent glycosides}

Infected and healthy cherry stems (Prunus yedoensis) were collected at the campus of The Hyogo University of Agriculture (Sasayama, Hyogo) in June, 1967. Both were air-dried and separated in two parts, the bark part (outer bark, inner bark, and cambium) and the wood part (sap wood and heart wood). Each chipped sample $(50 \mathrm{~g})$ was decocted with 200 $\mathrm{ml}$ of water by heating at $95^{\circ} \mathrm{C}$ for $2 \mathrm{hr}$, then the mixture was filtered. A similar process for the residue was repeated with $200 \mathrm{ml}$ of water, then with $150 \mathrm{ml}$. The combined filtrates and washings were evaporated in vacuo under a nitrogen stream to a final volume of about $50 \mathrm{ml}$. The concentrated solution was shaken with ethyl acetate until the organic layer showed no more color. To the aqueous layer was added $5.5 \mathrm{~g}$ of active carbon. The mixture was stirred for $1 \mathrm{hr}$ at $60 \sim 70^{\circ} \mathrm{C}$, then filtered. The filtrate was treated again with an additional $2.3 \mathrm{~g}$ of active carbon. The combined carbons were washed thoroughly with water, then were desorbed three times with $50 \mathrm{ml}$ portions of a methanol-28\% aq. ammonia mixture $(40: 1.5)$ and filtered. The combined filtrates were concentrated in vacuo under nitrogen to a volume of $5 \mathrm{ml}$. A one milliliter aliquot of the solution was applied to a thin-layer plate $(20 \times 20 \times 0.075 \mathrm{~cm})$ of Wako Gel B-5 and developed with a chloroform-ethanol mixture $(4: 1)$. Locations of the fluorescent glycosides were detected under an ultraviolet lamp. Each band which corresponded to the glycosides, was gathered by suction and the glycoside was eluted with methanol. The volume of the eluate was brought to 10 $\mathrm{ml}$ with methanol. The resulting turbidity which was attributed to a silica gel contaminant was removed by centrifugation. Thus clear supernatants were obtained which all fluoresced maximally at $443 \mathrm{~m} \mu$ when activated with $365 \mathrm{~m} \mu$ light, according to their glycosides which had a common fluorescent aglycon moiety. The amount of glycoside in each supernatant was fluorometrically determined on a Hitachi EPU-2 recording spectrophotometer equipped with a Hitachi L-3 attachment. The amount of FG-1 was estimated as gentisic acid-5- $\beta$-D-glucoside (see below), and FG-2 and FG-3, as gentisic acid-5rhamnosylglucoside. ${ }^{* 1}$ Results are shown in Table I. Amounts of these glycosides in

Table I. Contents of Fluorescent Glycoside IN Cherry Stems

Contents of $50 \mathrm{~g}$ samples are given.

\begin{tabular}{llrrr} 
& & $\begin{array}{c}\text { FG-1 } \\
(\mathrm{mg})\end{array}$ & $\begin{array}{c}\text { FG-2 } \\
(\mathrm{mg})\end{array}$ & $\begin{array}{r}\text { FG-3 } \\
(\mathrm{mg})\end{array}$ \\
\hline \multirow{3}{*}{ Infected } & Bark part & 2.4 & 90.2 & 6.2 \\
& Wood part & 1.7 & 24.2 & 4.2 \\
& Bealthy & 0.8 & 14.3 & 1.6 \\
& Bark part & 0.7 & 1.6 & 0.8 \\
\hline
\end{tabular}

infected stems were larger than those in healthy stems. Amounts of FG-1, FG-2, FG3 in the infected part were, respectively, 2.7, 7.2 , and 4.3 times those in the healthy part. The bark part contained generally large

*) FG-2 is identified with this compound. FG-3 also gives gentisic acid, glucose and rhamnose on hydrolysis. Details will be reported in subsequent papers. 


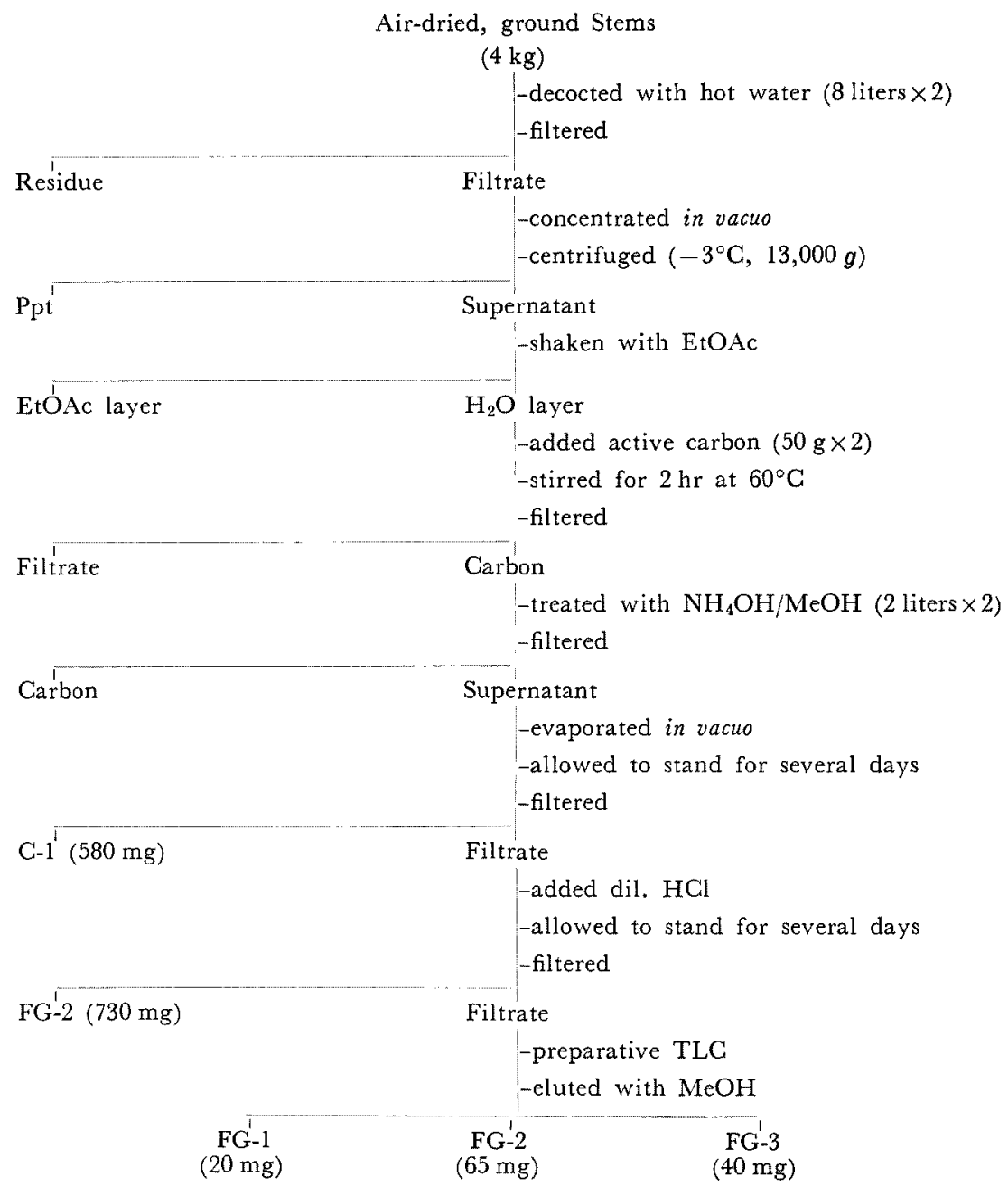

FIG. 1. Isolation Procedure for Fluorescent Glycosides.

amounts of the glycosides as compared with the wood part.

\section{Isolation of fluorescent glycosides}

Air-dried stems of the infected cherry plant (Prunus yedoensis), collected at the campus of The Hyogo University of Agriculture (Sasayama, Hyogo) in June, 1966, were chipped and ground in an iron mortar. Fluorescent compounds were isolated from the ground stems according to Fig. 1. Ground stems $(4 \mathrm{~kg})$ were decocted with 8 liters of water by heating them at $95^{\circ} \mathrm{C}$ for $2 \mathrm{hr}$. The water layer was decanted and the residue was treated again as specified above. The combined water layers and washings were evaporated to a volume of about 1.6 liters in vacuo under a nitrogen stream, then centrifuged $\left(-3^{\circ} \mathrm{C}, 13,000 \mathrm{G}\right)$. The supernatant was shaken with ethyl acetate until the solvent layer showed no more color. The aqueous layer was treated with $50 \mathrm{~g}$ of active carbon at $60^{\circ} \mathrm{C}$. The active carbon 
was filtered and the filtrate was treated again with $50 \mathrm{~g}$ of additional carbon. The combined carbons were washed thoroughly with water and sucked until they were almost dried. The dried carbon was suspended in 2 liters of methanol-aq. ammonia mixture $(40: 1.5)$. The suspension was stirred for $2 \mathrm{hr}$ at $60^{\circ} \mathrm{C}$, then filtered. This procedure was repeated twice. The combined filtrates were evaporated in vacuo under a nitrogen stream to a thick syrup. About seventy milliliters of absolute methanol was added to the syrup, and the resulting amorphus mass was filtered off. The filtrate was re-evaporated, and $580 \mathrm{mg}$ of a colorless crystal (C-1) was obtained. C-1 (mp 175 $178^{\circ} \mathrm{C}$ ) was filtered off and the filtrate was evaporated in vacuo under a nitrogen stream to a syrup. To the syrup $1 \mathrm{~N}$ hydrochloric acid was added dropwise until its blue fluorescence changed into yellow under an ultraviolet lamp. The mixture was allowed to stand for several days in a refrigerator, and $730 \mathrm{mg}$ of a crystalline mass (FG-2) was deposited. FG2 was filtered off, $\operatorname{mp} 152 \sim 155^{\circ} \mathrm{C}$. The filtrate

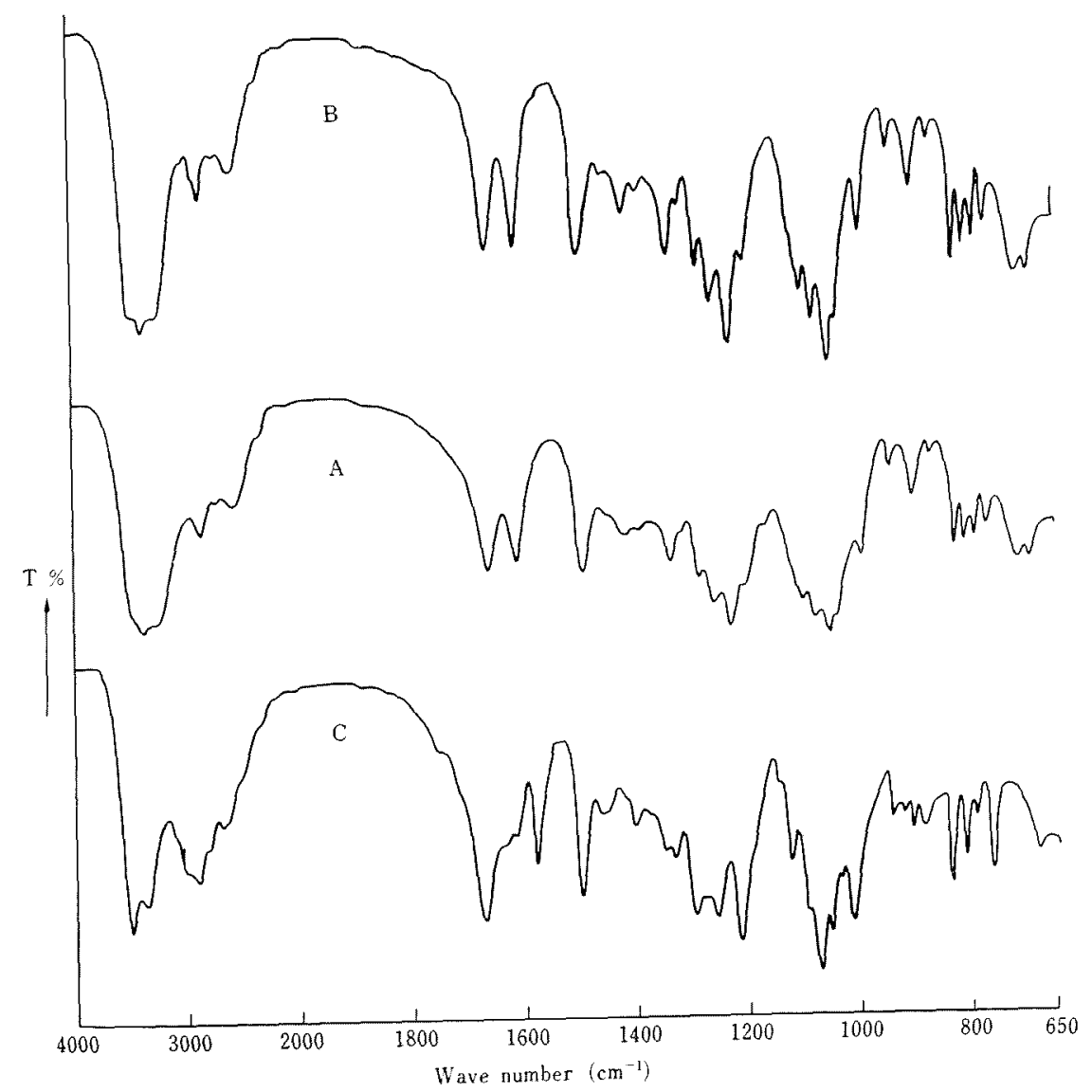

FIG. 2. Infrared Spectra of Gentisic Acid-glucosides (KBr).

A: FG-1 (mp $\left.124 \sim 126^{\circ} \mathrm{C}\right)$

B: Gentisic Acid-5- $\beta$-D-glucoside ( $\mathrm{mp} 124 \sim 126^{\circ} \mathrm{C}$ )

C: Gentisic Acid-5- $\beta$-D-glucoside (mp $128 \sim 129^{\circ} \mathrm{C}$ ) 
was applied to thin-layer plates $(20 \times 20 \times 0.075$ $\mathrm{cm})$ of Wako Gel B-5 and developed with a chloroform-ethanol mixture $(4: 1)$. Each band corresponding to a fluorescent glycoside was gathered by suction, and eluted with methanol. The eluate was concentrated in vacuo under a nitrogen stream to a thick syrup. Yields: FG1, $20 \mathrm{mg}$; additional FG-2, $65 \mathrm{mg}$; FG-3, $40 \mathrm{mg}$. The syrup $(20 \mathrm{mg}$ ) of FG-1 was dissolved in water and treated with active carbon as described above. The carbon was subjected to the desorption procedure with the methanolaq. ammonia mixture as above. After filtering the mixture the filtrate was evaporated to a thick syrup, and dil. hydrochloric acid was added. The solution was allowed to stand for several weeks, and FG-1 crystallized out. Recrystallization from water gave $5.4 \mathrm{mg}$ of colorless prisms, mp $124 \sim 126^{\circ} \mathrm{C} . \quad[\alpha]_{\mathrm{D}}^{25}-62.5^{\circ}$ ( $c=0.07$, methanol). Its IR spectrum is shown in Fig. 2. UV $\lambda_{\max }^{\mathrm{MeOH}} \mathrm{m} / \ell(\varepsilon): 235$ (4200), 324 (3110). Fluorescent peak: $443 \mathrm{~m} \mu$ (in methanol, activated at $365 \mathrm{~m} \mu$ ). Color reaction: ferric chloride, violet; methyl red, red; diazotized sulfanilic acid, faint brown. For Fehling's solution, gave a negative test, after hydrolysis, a positive test.

\section{Chemical structure of $F G-I$}

Acid hydrolysis. Syrupy FG-1 (ca. $20 \mathrm{mg}$ ) was dissolved in $0.2 \mathrm{~N}$ sulfuric acid and heated on a boiling water both for $2 \mathrm{hr}$. The paper chromatogram of the mixture (Fig. 3) exhibited new two spots, Rf 0.89 corresponding to gentisic acid, and $R f 0.30$ corresponding to glucose. The mixture was shaken with ether. This ethereal solution was washed with water, then dried over anhydrous sodium sulfate and evaporated. The residue was crystallized out Sublimation of the crystals under reduced pressure $\left(110^{\circ} \mathrm{C} / 18 \mathrm{mmHg}\right)$ gave $5.5 \mathrm{mg}$ of colorless needles, mp $199 \sim 202^{\circ} \mathrm{C}$ (in a sealed tube). MS m/e: $154\left(\mathrm{M}^{+}\right)$. Anal. Found: C, 54.57; $\mathrm{H}, 3.57$. Calcd. for $\mathrm{C}_{7} \mathrm{H}_{6} \mathrm{O}_{4}: \mathrm{C}, 54.55$; $\mathrm{H}, 3.920^{\circ}$. UV absorption maxima (237 and

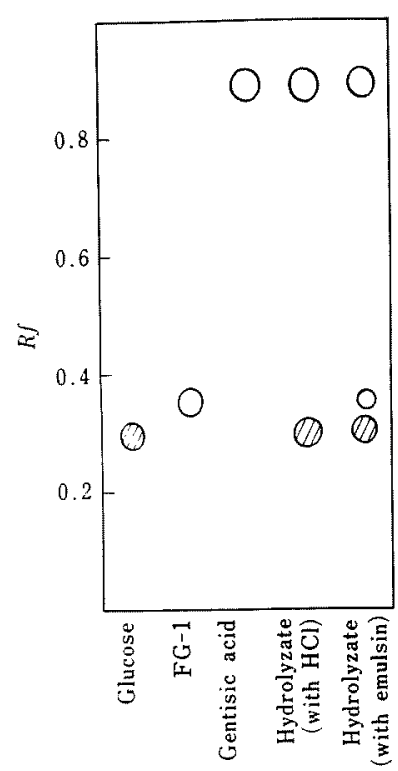

FIG. 3. Paper Chromatograms of the Hydrolyzate of FG-1. Solvent: $n$-BuOH-AcOH- $\mathrm{H}_{2} \mathrm{O}(6: 1: 1)$.

$\mathrm{O}$ : Fluorescence under UV lamp

: Positive to Aniline Hydrogen Phthalate

$337 \mathrm{~m} \mu$, in ethanol), the IR spectrum, and paper chromatographic behavior were in good agreement with those of authentic gentisic acid. Thus, the aglycon in FG-1 is identified with gentisic acid.

The aqueous layer was neutralized by addition of barium carbonate, then filtered. The filtrate was treated with Glucostat (Washington Biochemical Corp.), after which it turned dark blue. The paper chromatogram of the mixture did not exhibit any spot corresponding to sugar. Consequently, the sugar moiety of FG-1 was considered to be glucose.

Mol ratio determination of glucose and gentisic acid in FG-1. FG-1 (1.5 mg) was hydrolyzed with $0.5 \mathrm{~N}$ hydrochloric acid as above. After evaporation of the hydrolyzate solution, the dry residue was trimethylsilylated according to the method reported by Kagan and Mobry,

3) J. Kagan and T. J. Mobry, Anal. Chem., 37, $288(1965)$. 
then gas-chromatographed on a Hitachi K-53 gas chromatograph equipped with FID. A stainless steel column $(1 \mathrm{~m} \times 3 \mathrm{~mm})$ packed with $10{ }^{\circ}$ ' Silicone SE-52 on 60/80 Chromosorb W was used. The carrier gas was nitrogen at a flow rate of $30 \mathrm{ml}$ per min. The temperature of the oven was $200^{\circ} \mathrm{C}$, and that of the injection block was $280^{\circ} \mathrm{C}$. As a standard, an equimolar mixture of glucose and gentisic acid was treated with hydrochloric acid then trimethylsilylated, and gaschromatographed, as was FG-1. Both chromatograms showed three peaks; corresponding to $\alpha$-glucose, $\beta$-glucose, and gentisic acid. In order to evaluate the relative amounts of glucose and gentisic acid, the peak area was cut off and weighed. With FG-1, the ratio of the peak area of gentisic acid to that of $\alpha$-glucose plus $\beta$-glucose was $1: 1.42$; with the standard it was $1: 1.36$. Thus the mol ratio of gentisic acid to glucose in FG-1 is $1: 1$.

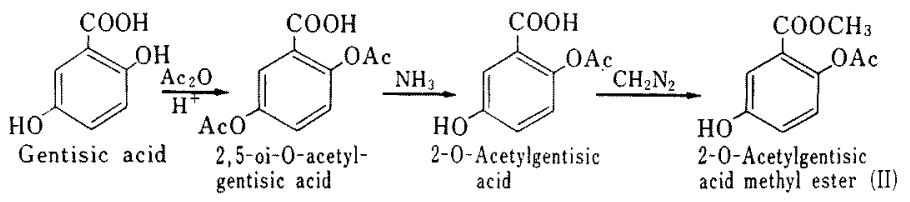

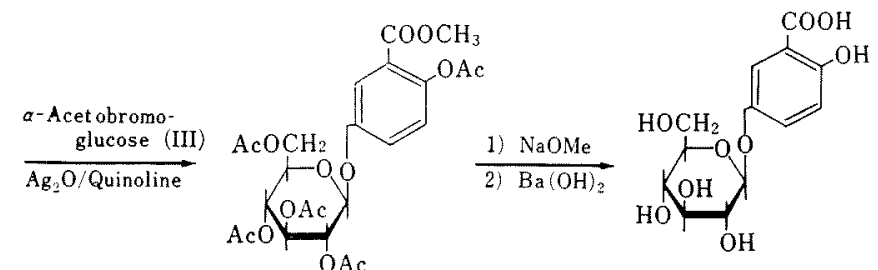

2-O-Acetylgentisic acid methyl ester5-(tetraacetyl- $\beta$-D-glucopyranoside), (IV)

Gentisic acid-5- $\beta$ - Dglucopyranoside, (I)

a) Gentisic Acid-5- $\beta$-D-glucopyranoside

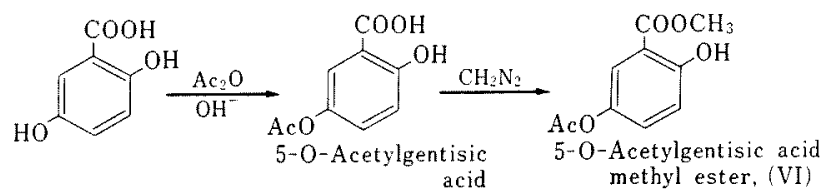

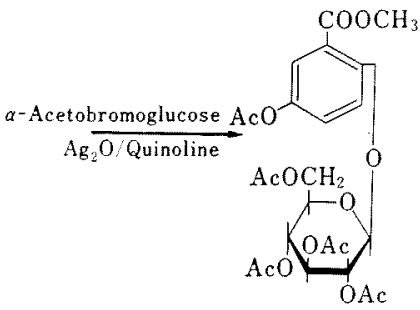

5- $\mathrm{O}$-Acetylgentisic acid methyl ester 2 - (tetraacetyl- $\beta$-D-glucopyranoside, (VII

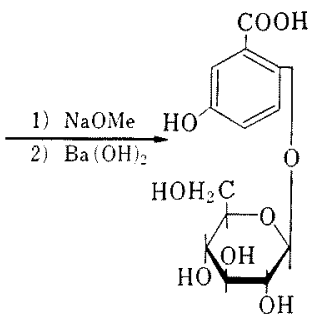

Gentisic acid-2- $\beta$ b-glucopyranoside, (V)

b) Gentisic Acid-2-3-D-glucopyranoside

FIG. 4. Schema for Syntheses of Gentisic Acid-glucoside. 
Hydrolysis of FG-1 with emulsin. To a solution of FG-1 (ca. $2 \mathrm{mg})$ in $2 \mathrm{ml}$ of $0.2 \mathrm{M}$ acetate buffer ( $\mathrm{pH} 7.0$ ) was added $5 \mathrm{mg}$ of emulsin. This mixture was kept at $30^{\circ} \mathrm{C}$ for $20 \mathrm{hr}$, then paperchromatographed. FG-1 was hydrolyzed to give glucose and gentisic acid (Fig. 3). From this result a $\beta$-glucosidic linkage in FG-1 was suggested.

IV. Synthesis of gentisic acid-5- and 2- $-\beta-D-$ glucopyranoside

Previously reported methods, $s^{4}$ were used with a slight modification. The process is outlined in Fig. 4.

A. Gentisic acid-5- $\beta$-D-glucopyranoside (I). 2-O-Acetyl-gentisic acid methyl ester (II), $\mathrm{mp}$ $99.5 \sim 100^{\circ} \mathrm{C}, \mathrm{NMR} \quad \delta_{\mathrm{Me}_{4} \mathrm{Sl}_{3}}^{\mathrm{CDCl}_{3}}: 2.33$ (3H, s., 2$\left.\mathrm{OCOCH}_{3}\right), 3.83\left(3 \mathrm{H}\right.$, s., $\left.\mathrm{COOCH}_{3}\right), 6.90(2 \mathrm{H}$ aryl $\mathrm{H}-3$ and $\mathrm{H}-4), 7.53$ ( $1 \mathrm{H}, \mathrm{t} ., J=1 \mathrm{~Hz}$, aryl H-6), was prepared ${ }^{41}$ from gentisic-acid via 2,5-di-O-acetylgentisic acid, and then 2-Oacetylgentisic acid, ${ }^{6 /} \alpha$-Acetobromoglucose (III) was prepared according to Lemieux, ${ }^{71} \mathrm{mp}$ $88 \sim 89^{\circ} \mathrm{C}$. One gram of II, $2 \mathrm{~g}$ of III, and $0.56 \mathrm{~g}$ of freshly prepared silver oxide ${ }^{81}$ were kneaded with $1 \mathrm{ml}$ of freshly prepared quinoline. The slurry was allowed to stand in a desiccator in which air was replaced by nitrogen. After $3 \mathrm{hr}$ the slurry was triturated with chloroform, and centrifuged. The process was repeated twice. The combined supernatants were washed in the following order: twice with $10 \%$ hydrochloric acid, twice with water, four times with $10 \%$ sodium bicarbonate solution, and four times with water. The chloroform layer was dried over calcium chloride and evaporated to a thick syrup. The

4) G. Wagner, Arch. Pharm, 291, 278 (1958).

5) A. Zane and S. H. Wender, J. Org. Chem., 29, 2812 (1964).

6) M. Bergmann and D. Dangschat, Ber., 52B, 371 (1919).

7) R. U. Lemieux, "Method in Carbohydrate Chemistry," Vol. II, Academic Press, 1963, p. 221.

8) E. L. Hirst and E. Percival, ibid., p. 146. syrup was dissolved in hot methanol, and allowed to stand for several days, which gave $700 \mathrm{mg}$ of a crystalline mass. Recrystallization from methanol gave colorless needles of 2-Oacetylgentisic acid methyl ester-5-(tetra-Oacetyl- $\beta$-D-glucopyranoside) (IV), mp 121 $122^{\circ} \mathrm{C}$, NMR $\delta_{\mathrm{Me}_{4}{ }^{\mathrm{CD}}:}: 2.04,2.07(12 \mathrm{H}$, glucose$\left.\mathrm{OCOCH}_{3}\right) ; 2.28\left(3 \mathrm{H}\right.$, s., aryl 2-OCOCH$\left.{ }_{3}\right), 3.85$ ( $3 \mathrm{H}$, s., $\mathrm{COOCH}_{3}$ ), 4.22 5.30 (glucose-CH-), $7.20(2 \mathrm{H}$, aryl $\mathrm{H}-3$ and $\mathrm{H}-4), 7.53(1 \mathrm{H}, \mathrm{t} ., J=$ 1 , aryl $\mathrm{H}-6)$. IV (300 $\mathrm{mg}$ ) was dissolved in $15 \mathrm{ml}$ of $0.5 \mathrm{~N}$ sodium methylate in methanol and refluxed for $30 \mathrm{~min}$. The mixture was neutralized with sulfuric acid and centrifuged to remove resulting sodium sulfate. The supernatant was evaporated under reduced pressure to a thick syrup. The syrup was dissolved in $7 \mathrm{ml}$ of saturated barium hydroxide solution and allowed to stand for $5 \mathrm{hr}$ at room temper. ature. The mixture was neutralized by bubbling carbon dioxide through it, then it was centrifuged. The supernatant was concentrated in vacuo under a nitrogen stream to a thick syrup. To the syrup was added drop by drop $1 \mathrm{~N}$ hydrochloric acid under an ultraviolet lamp until the blue fluorescence turned yellow, then the mixture was allowed to stand in a refrigerator. After several days $92.3 \mathrm{mg}$ of colorless prisms were deposited. Recrystallization from water gave pure 1 which melted at $124 \sim 126^{\circ} \mathrm{C}$. Anal. ${ }^{* 1}$ Found: C, 49.40; H, 4.98. Calcd. for $\mathrm{C}_{13}$ $\mathrm{H}_{16} \mathrm{O}_{9}: \mathrm{C}, 49.37 ; \mathrm{H}, 5.100^{\circ} .[\alpha]_{\mathrm{D}}^{95}-65.0^{\circ}(c=0.1$, methanol).

\section{B. Gentisic acid-2- $\beta$-D-glucopyranoside $(V)$}

5-O-Acetylgentisic acid methyl ester (VI),

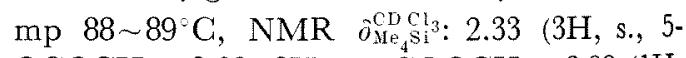
$\left.\mathrm{OCOCH}_{3}\right), 3.88\left(3 \mathrm{H}\right.$, s., $\left.\mathrm{COOCH}_{3}\right), 6.99(1 \mathrm{H}$, d., $J=8$, aryl $\mathrm{H}-3), 7.23(1 \mathrm{H}, \mathrm{q}$. , aryl $\mathrm{H}-4$, $J=3$, and 8$), 7.58(1 \mathrm{H}, \mathrm{d},, J=3$, aryl $\mathrm{H}-6)$,

* Elementary analysis was carried out after drying a sample for $15 \mathrm{hr}$ over $\mathrm{P}_{2} \mathrm{O}_{5}$ at $80^{\circ} \mathrm{C}$ in vacuo. Zane and Wender ${ }^{5}$ ) obtained a dihydrate crystal ( $\mathrm{mp}$ $98 \sim 100^{\circ} \mathrm{C}$ ) from hot water and a sesquihydrate form (mp 126 128 $\mathrm{C}$ ) after dryness $\left(6 \mathrm{hr}\right.$, over $\mathrm{P}_{2} \mathrm{O}_{5} 110^{\circ} \mathrm{C}$, in vacuo). 
10.58 (1H, s., 2-OH), was prepared ${ }^{4)}$ from gentisic acid via 5-O-acetylgentisic acid, ${ }^{9 \prime} \mathrm{mp}$ $88 \sim 89^{\circ} \mathrm{C}$. One gram of VI and $2 \mathrm{~g}$ of III were treated with silver oxide as specified in $A$. The resulting 5-O-acetylgentisic acid methyl ester-2-(tetra-O-acetyl- $\beta$-D-glucoside) (VII), mp $135 \sim 136^{\circ} \mathrm{C}, \mathrm{NMR} \delta_{\mathrm{Ne}_{4} \mathrm{~S}_{1}}^{\mathrm{CDCl}_{3}}: 2.04,2.08(12 \mathrm{H}$, glucose- $-\mathrm{OCOCH}_{3}$ ), 2.33 (3H, s., aryl 5- $\mathrm{OCOCH}_{3}$ ), 3.88 (3H, s., $\left.\mathrm{COOCH}_{3}\right), 6.99$ ( $1 \mathrm{H}$, d., $J=8$, aryl $\mathrm{H}-3), 7.23,(1 \mathrm{H}, \mathrm{q} ., J=3$, and 8 , aryl $\mathrm{H}-4$ ), $7.65(1 \mathrm{H}, \mathrm{d} ., J=3$, aryl $\mathrm{H}-6)$, was de-esterified first with sodium methylate, then by barium hydroxide. Crystallization of the de-esterified product from dil. hydrochloric acid gave $15 \mathrm{mg}$ of fine needles of V. mp $128 \sim 129^{\circ} \mathrm{C}$. (lit., ${ }^{51}$ $\mathrm{mp} 129 \sim 131^{\circ} \mathrm{C}$ for monohydrate), $[\alpha]_{D}^{2+4}-67.8^{\circ}$ $(c=0.1$, methanol).

\section{DISCUSSION}

Gentisic acid is extensively distributed in the plant kingdom. ${ }^{10,111}$ Gentisic acid-glycoside, however, was scarcely found in boron-deficient sunflower plants, as reported by Watanabe and his co-workers. ${ }^{12)}$ In cherry (Prunus yedoensis) stems, we found three new kinds of gentisic acid-glycosides (FG-1, FG-2, and FG-3). The contents of these glycosides were generally higher in the dark part than in the wood part; and they, especially FG-2, were remarkably increased when stems were infected by Taphrina ziesneri. The amount of FG-2 in the infected bark part reached $0.18,6$ in dry matter. On the other hand, the bark of some other Prunus species with resistances to "Witch's Broom" contain large amounts of these glycosides as compared with the bark of healthy Prunus yedoensis. ${ }^{13}$

9) R. Lesser and G, Gad, Ber., 59B, 233 (1926).

10) M. Tomaszewski, Bull. Acad. Polon. Sci. Ses. Biol., 8, 61 (1960) [C. A. 54, I9865 (1960)].

11) L. A. Griffiths, Nature, 182, 733 (1958); idem, J. Exptl. Botany, 10, 437 (1959).

12) R. Watanabe, W. Chorney, J. Skokand and

S. H. Wender, Phytochem., 3, 391 (1964).

13) Unpublished data.
Antifungal activities of gentisic acid ${ }^{141}$ or its esters ${ }^{15)}$ were reported. However, in the test against $T$ wiesneri, ${ }^{13)}$ the activity was not so strong. (Threshold concentrations were $1 / 100$ mol for gentisic acid, and $6 / 100 \mathrm{~mol}$ for the gentisic acid-glycosides.) Plant hormone and growth regulating tests of the glycosides were also negative (Avena test, rice lamina-joint test and germination test of rice and rape seeds). ${ }^{131}$

As yet, no reasonable explanation for the large accumulation of these compounds in the infected stems of Prunus yedoensis can be offered.

FG-1 which amounted to $0.005 \%$ of the dry infected bark and $0.003 \%$ of the dry infected wood, was a gentisic acid-monoglucoside. In gentisic acid-monoglucoside, there must be three kinds of position isomers; gentisic acid2- and 5-glucoside, and 1-O-gentisoyl glucose. Each isomer can be further classified into two anomers, $\alpha$ - and $\beta$-anomer, even if configuration of the glucose moiety is restricted to D-form. Gentisic acid methyl ester resembles 1-O-gentisoyl glucose at the point where the two hydroxyls of the hydroquinone type are liberated in both molecules. The ester exhibits dark blue fluorescence under an ultraviolet lamp, and reacts readily with alkaline silver nitrate at room temperature. On the other hand, FG-1 did not exhibits these properties. Hence, 1-O-gentisoyl glucose is tentatively excluded from our considerations. The other two glucosides are composed of two anomers, as mentioned above. To decide the probable linkage of the glucose moiety in FG-1, the optical rotation was calculated according to Hudson's rule. ${ }^{16)}$ The values ${ }^{17 !}$ of rotations of ethyl $\alpha$ - and $\beta$-D-glucoside (I), or of phenyl

14) L. E. Loveless, E. Spoerl and T. H. Weisman, J. Bacteriol., 68, 647 (1954).

15) H. L. Klöpping and G. J. M. van der Kerk, Nature, 167, 996 (1951); G. Carvajal, S. Penna and E. J. Carvajal, Rev. Latioam. Microbiol, 5, 45 (1962).

16) C. S. Hudson, J. Am. Chem. Soc., 31, 66 (1909); ibid., 38, 1566 (1916).

17) Y. Tsuzuki, "Tô-rui." I wanami-Shoten, Tokyo, 1954, p. 54 . 
TABle II. Optical Rotations of Gentisic Acid-glucosides

\begin{tabular}{|c|c|c|c|c|c|c|}
\hline & \multicolumn{4}{|c|}{ Calculated } & \multicolumn{2}{|c|}{ Observed } \\
\hline & \multicolumn{2}{|c|}{ from I } & \multicolumn{2}{|c|}{ from II } & \multirow[b]{2}{*}[\alpha]{$_{\mathrm{D}}$} & \multirow[b]{2}{*}{$\mathrm{M}_{\mathrm{D}}$} \\
\hline & {$[\alpha]_{\mathrm{D}}$} & $\mathrm{M}_{\mathrm{D}}$ & {$[\alpha]_{\mathrm{D}}$} & $\mathrm{M}_{\mathrm{D}}$ & & \\
\hline Gentisic acid- $\alpha$-D-glucoside & 100 & 31,360 & 146 & 46,330 & & \\
\hline Gentisic acid- $\beta$-D-glucoside & -22 & $-6,950$ & -57 & $-18,190$ & & \\
\hline FG-1 & & & & & -62.5 & $-19,750$ \\
\hline Gentisic acid-5- $\beta$-D-glucoside & & & & & -65.0 & $-20,540$ \\
\hline Gentisic acid-2- $\beta$-D-glucoside & & & & & -67.8 & $-21,420$ \\
\hline
\end{tabular}

I: Data for ethyl glucosides

II: Data for phenyl glucosides

Table III. Properties of FG-1, and Gentisic Acid-2- and 5- $\beta$-D-Glucopyranoside

\begin{tabular}{lcccc} 
& $\mathrm{UV} \lambda_{\mathrm{max}}^{\mathrm{MeOH}}(\mathrm{m} \mu)$ & $\begin{array}{c}\text { Color of fluorescence } \\
\text { (under UV lamp) }\end{array}$ & Rf Value (TLC) ${ }^{a}$ \\
\hline FG-1 & 235 & 324 & blue & 0.10 \\
Gentisic acid-2- $\beta$-D-glucopyranoside & 294 & & dark blue & 0.08 \\
Gentisic acid-5- $\beta$-D-glucopyranoside & 235 & 324 & blue & 0.10 \\
\hline
\end{tabular}

a) The solvent used in TLC was $\mathrm{CHCl}_{3} / \mathrm{EtOH}(4: 1)$.

$\alpha$ - and $\beta$-D-glucoside (II) were used as the basis of the calculation. The A value calculated from the data of $I$ is 19,155, and from the data of II, 32,260. The B value calculated from the data of $\mathrm{I}$ is 12,205 , and from the data of II, 14,070. Results obtained from these values are given in Table II. The observed specific rotation $(-62.5)$ was considerably larger than the value $(-22)$ calculated from the data of $\mathrm{I}$, but was similar to that $(-57)$ from the data of II. Furthermore, FG1 was hydrolyzed with emulsin. Thus, the glucosidic linkage in FG-1 was tentatively assigned to $\beta$ form.

As a next step it was necessary to determine the position of the attachment of the glucose moiety to gentisic acid in FG-1. Although the expected 5- or 2- $\beta$-D-glucoside had synthesized by Zane and Wender, ${ }^{51}$ the described melting point of both glucosides approximated each other. IR spectra and specifie rotations were not reported. To identify FG-1 the two isomers were synthesized and their properties were compared with those of FG-1. The IR spectrum (Fig. 1), UV absorption maxima
(Table III), the thin-layer chromatogram (Table III), the melting point, and specific rotation (Table II) of FG-1 were all in good agreement with those of gentisic acid-5- $\beta$-D-glucoside.

The compound in crystalline form was first isolated by us from the $T$. wiesneri-infected cherry plant. Syrupy gentisic acid-5- $\beta$-D-glucopyranoside had already been isolated from boron-deficient sunflower plants as stated and was later identified by Zane and Wender ${ }^{181}$ on the basis of its UV spectrum and its paperchromatographic behavior.

Acknowledgements. We are indebted to Dr. E. Hamaguchi, Emeritus professor of The Hyogo University of Agriculture, for his helpful guidance. We also wish to express our gratitude to Dr. H. Tanaka Na. goya University, for NMR spectra measurement. Thanks are also due to Messrs. H. Katayama, K. Hirano and $\mathrm{K}$. Nishikawa for their technical assistance, and to Misses M. Hamaji and H. Mase for microanalysis. The authors also would like to thank the Nissei Industry Co. for measurement of mass spectra and microanalyses.

18) A. Zane and S. H. Wender, Chem. E्E Ind., $1964,1835$. 